\title{
Структура методик измерения параметров ФПУ второго поколения
}

\author{
А.В. Полесский \\ АО «НПО «Орион», Москва 111538, Косинская, 9 \\ тел:+7 (499) 374-4884, эл. почта: av22236@bk.ru
}

DOI 10.34077/RCSP2019-55

Нормативная база методик измерения фотоприёмников и фотоприемных устройств (ФПУ) в России не обновлялась с 80-х годов XX века [1]. За этот период в России был освоен выпуск ФПУ второго поколения, для которых используется иная система параметров и измерительное оборудование с высокой степенью автоматизации.

К настоящему времени в России сложились предпосылки к формированию стандартов, измерения параметров ФПУ второго поколения. Как и в стандарте [1], в перспективном стандарте должны быть решены вопросы прослеживаемости измерений и определения их погрешности.

Для решения поставленной задачи в АО «НПО «Орион» были выполнена работа по упорядочиванию структуры методик измерения параметров ИК и УФ ФПУ второго поколения.

Помимо основных методик измерения, которые наиболее полно приведены в [2,3], в комплексную структуру методик измерения включены методики контроля вспомогательного оборудования (блоки электронной обработки, программное обеспечение, источники излучения и т. д.), поскольку данное оборудование вносит погрешности в результат измерения. При этом для вспомогательного оборудования должны быть нормированы некоторые специфические параметры, не отраженные в нормативной документации (описании типа и др.).



На основании приведенной комплексной структуры методик измерения параметров ИК и УФ ФПУ второго поколения возможно решение задачи метрологического обеспечения: обеспечить состояние измерений, при котором их результаты выражены в узаконенных единицах измерений (величин) и оценены неопределенности, или пределы погрешностей результатов измерений не выходят за установленные пределы.

Данная структура имеет большой потенциал развития и впоследствии может стать основой соответствующего Государственного стандарта Российской Федерации.

\section{Лumepamypa}

[1] ГОСТ 17772-88. Приемники излучения и устройства приемные полупроводниковые фотоэлектрические. Методы измерения фотоэлектрических параметров и определения характеристик. - М.: Государственный комитет СССР по стандартам, 1988. - 65 с.

[2] Полесский А. В. // Успехи прикладной физики. 2017. Т. 5. № 4. С. 350-359.

[3] Деомидов А. Д. и др. // Прикладная физика. 2014. № 6. С. 87-92. 